Check for updates
Cite this: RSC Adv., 2018, 8, 29928

\section{Design and controllable synthesis of ethylenediamine-grafted ion imprinted magnetic polymers for highly selective adsorption to perchlorate $\dagger$ t}

\author{
Haoyu Shen, (D) *a Meina Sun, ${ }^{b}$ Meiqin $\mathrm{Hu}^{\mathrm{a}}$ and Jinjin Cheng ${ }^{\mathrm{a}}$
}

A series of ethylenediamine-grafted ion imprinted magnetic polymers ( $\mathrm{Fe}_{3} \mathrm{O}_{4} \mathrm{Q}$ IIPs) were synthesized via ultrasonic assisted suspension polymerization with perchlorate $\left(\mathrm{ClO}_{4}{ }^{-}\right)$as an ion imprinting template. They were characterized by XRD, EA, VSM, FTIR and XPS and applied as adsorbents for $\mathrm{ClO}_{4}{ }^{-}$removal from aqueous solutions. The effects of the usage amount of crosslinking agent divinylbenzene (DVB) used for preparation on the structure and the adsorptive performance of $\mathrm{Fe}_{3} \mathrm{O}_{4}$ @lIPs were investigated. The results show that the $\mathrm{Fe}_{3} \mathrm{O}_{4}$ @ll Ps have an average size of 200-800 nm, which increases with the increase of the amount of DVB from 0 to $2 \mathrm{~g}$ during the preparation process. The saturation magnetization intensities are at 35.6-42.8 emu g ${ }^{-1}$, which decrease with the increase of the usage amount of DVB. The addition of DVB is beneficial to the formation and stability of the ion imprinted cavity of $\mathrm{Fe}_{3} \mathrm{O}_{4}$ Qll Ps. The effects of the solution $\mathrm{pH}$ value, initial concentration of $\mathrm{ClO}_{4}{ }^{-}$, and adsorption time on the adsorption properties of $\mathrm{ClO}_{4}{ }^{-}$in aqueous solutions were investigated. The results show that the adsorption capability is affected significantly by solution $\mathrm{pH}$ value and reaches the maximum adsorption capacity at $\mathrm{pH}$ 3.0. The best adsorption capacity and selectivity of $\mathrm{Fe}_{3} \mathrm{O}_{4} \mathrm{Q}$ IIPs to $\mathrm{ClO}_{4}{ }^{-}$can be obtained when the usage amount of DVB is at $0.5 \mathrm{~g}$ for synthesis. The adsorption mechanisms might include both ion exchange and electrostatic interaction. The isothermal adsorption curves mainly obey the Langmuir model with the theoretical maximum adsorption capacities $\left(q_{\mathrm{m}, \mathrm{c}}\right)$ at $76.92-111.1 \mathrm{mg} \mathrm{g}^{-1}$ and the experimental maximum adsorption capacities $\left(q_{\mathrm{m}, \mathrm{e}}\right)$ at $75.7-108.9 \mathrm{mg} \mathrm{g}^{-1}$, respectively, which are much higher than those of the non-ion imprinted material $\left(\mathrm{Fe}_{3} \mathrm{O}_{4} \mathrm{QNIP}, q_{\mathrm{m}, \mathrm{NIP}}\right.$ : $q_{\mathrm{m}, \mathrm{c}}$ at $60.61 \mathrm{mg} \mathrm{g}^{-1}$ and $q_{\mathrm{m}, \mathrm{e}}$ at $59.0 \mathrm{mg} \mathrm{g}^{-1}$ ). The adsorption kinetic studies show that the adsorption processes reach equilibrium within $10 \mathrm{~min}$ and the kinetic data are well fitted to the pseudo-second-order model. There is almost no interference by the coexisting anions for the selective adsorption of $\mathrm{ClO}_{4}^{-}$, with a imprinting factor $(\alpha)$ at 1.8, and selectivity factor $(\beta)$ larger than 5.9 for several kinds of common coexisting anions, respectively. The $\mathrm{Fe}_{3} \mathrm{O}_{4}$ @llPs are ideal candidates for removal of $\mathrm{ClO}_{4}{ }^{-}$from aqueous solution.

Received 18th July 2018

Accepted 17th August 2018

DOI: $10.1039 / c 8 r a 06085 a$

rsc.li/rsc-advances
$\mathrm{ClO}_{4}{ }^{-}$has also been widely used in clinical treatment of hyperthyroidism caused by immune system defects and clinical examination of thyroxine secretion, etc. ${ }^{4}$ Since the charge and ionic radius of $\mathrm{ClO}_{4}{ }^{-}$are very close those of the iodine ion $\left(\mathrm{I}^{-}\right)$, $\mathrm{ClO}_{4}{ }^{-}$has been found to inhibit the uptake of iodine and disturb the synthesis of the thyroid hormone, which would affect the development of the central nervous system in newborns and induce thyroid cancer. ${ }^{5}$

Because of its high water solubility and stability, the degradation of $\mathrm{ClO}_{4}^{-}$in the natural environment needs several decades or even longer. ${ }^{5}$ Conventional treatment processes, such as coagulation, precipitation, filtration and disinfection, cannot remove $\mathrm{ClO}_{4}{ }^{-}$efficiently. ${ }^{6,7}$ Current technologies for $\mathrm{ClO}_{4}{ }^{-}$removal from drinking water and groundwater include
${ }^{a}$ Ningbo Institute of Technology, Zhejiang University, Ningbo, 315100, China. E-mail: hyshen@nit.zju.edu.cn; Tel: +86-574-88130130

${ }^{b}$ Greentown Agricultural Testing Technology Co., Ltd, Hangzhou, 310052, China $\dagger$ Dedicated to Prof. Dai-Zheng Liao on the occasion of his 80th birthday.

\$ Electronic supplementary information (ESI) available. See DOI: 10.1039/c8ra06085a 
adsorption, ${ }^{8,9}$ ion exchange, ${ }^{10,11}$ chemical reduction ${ }^{12-14}$ bioremediation, ${ }^{\mathbf{1 4}, 15}$ etc.

An ion imprinted polymer (IIP) ${ }^{\mathbf{1 6 - 1 8}}$ is able to recognize ions whilst keeping the unique virtues of molecular imprinting polymers (MIP), i.e., structure predictability, recognition specificity and application universality. Owing to special coordination or electrostatic interactions, IIPs are generally compatible with aqueous media and have advantages over most MIPs. ${ }^{16}$ IIPs can achieve effective identification of water-soluble ions. However, centrifugation or long-time subside is still needed for the separation of the IIPs from the post-adsorption solution, which is time-consuming and inefficient. Recently, functional group grafted nano-magnetic particles (FNMPs) have attracted greats attention because of their unique magnetic and structural properties. ${ }^{19-24}$ It would be desirable if the high selectivity, good adsorptive efficiency and fast magnetic separation were associated by grafting the IIPs on the surface of the FNMPs via such a three-in-one strategy. The obtained material would be expected to not only retain the high selective recognition of IIPs to the target ion, but also to achieve the goal of high adsorption capacity, as well as fast removal of the contaminant.

Herein, in this work, we report the design and successful synthesis of a serial of core-shell microspheres ion imprinted magnetic polymers $\left(\mathrm{Fe}_{3} \mathrm{O}_{4}\right.$ @IIPs), by using $\mathrm{ClO}_{4}{ }^{-}$as the template. Their applications as adsorbents for $\mathrm{ClO}_{4}{ }^{-}$removal from aqueous solutions were studied. By varying the usage amount of DVB during the preparation procedure, the structure and adsorption properties on $\mathrm{ClO}_{4}{ }^{-}$were tuned. Based on the investigation of the effects of solution $\mathrm{pH}$ values and common co-existing anions on the adsorption properties, adsorption thermodynamic, kinetic parameters, as well as comparing with that of the non-ion imprinted magnetic polymer composite ( $\mathrm{Fe}_{3} \mathrm{O}_{4} @ \mathrm{NIP}$ ), the adsorption mechanism was intensively studied. The results show that the $\mathrm{Fe}_{3} \mathrm{O}_{4} @$ @IIPs are ideal candidates for adsorption and removal $\mathrm{ClO}_{4}{ }^{-}$from aqueous solution.

\section{Experimental}

\subsection{Materials}

Ferric chloride $\left(\mathrm{FeCl}_{3} \cdot 6 \mathrm{H}_{2} \mathrm{O}\right)$, sodium acetate (NaAc), ethylene glycol (EG), potassium perchlorate $\left(\mathrm{KClO}_{4}\right)$, were analytical grade, and purchased from Sinopharm Chemical Reagent Co., Ltd. ethylenediamine (EDA), styrene (St), divinylbenzene (DVB) and glycidylmethacrylate (GMA) were supplied by Aladdin Chemical Reagent Co., Ltd. (Shanghai, China) and purified by vacuum distillation. Benzoyl peroxide (BPO) was purchased from J\&K Chemical (99\%) and used as an initiator without further purification. Distilled water was used to prepare all the solutions. $0.1 \mathrm{~mol} \mathrm{~L}^{-1} \mathrm{HCl}$ and $0.1 \mathrm{~mol} \mathrm{~L}^{-1} \mathrm{NaOH}$ solutions were used for $\mathrm{pH}$ adjustment.

\subsection{Synthesis of $\mathrm{nFe}_{3} \mathrm{O}_{4}$ @IIPs}

The overall preparation of $\mathrm{ClO}_{4}{ }^{-}$-imprinted magnetic polymers ( $\left.\mathrm{nFe}_{3} \mathrm{O}_{4} @ I I P s\right)$ is depicted in Scheme 1.4 kinds of $\mathrm{nFe}_{3} \mathrm{O}_{4} @$ @IIPs, as listed in Table 1, were prepared by the following steps via suspension polymerization and surface imprinting technique.
The preparation procedure of $\mathrm{nFe}_{3} \mathrm{O}_{4}$ @IIP-D0.5-G8 (no. 2) was taken as an example for discussion.

Firstly, the nano- $\mathrm{Fe}_{3} \mathrm{O}_{4}\left(\mathrm{nFe}_{3} \mathrm{O}_{4}\right.$, no. 6) was produced using a polyol-media one-pot solvothermal method (Scheme 1(a)). $4.0 \mathrm{~g}$ of $\mathrm{FeCl}_{3} \cdot 6 \mathrm{H}_{2} \mathrm{O}$, and $12.0 \mathrm{~g}$ of $\mathrm{NaAc}$ were dissolved in $120 \mathrm{~mL}$ ethylene glycol (EG). This solution was stirred vigorously at room temperature for $10 \mathrm{~min}$ to form a stable orange solution and then transferred to a Teflon-lined autoclave and heated at $180{ }^{\circ} \mathrm{C}$ for $8 \mathrm{~h}$. After the autoclave cooled to room temperature, the resulting $\mathrm{nFe}_{3} \mathrm{O}_{4}$ was isolated under magnetic field and washed with water and ethanol to remove redundant reagents and impurities. The as-prepared $\mathrm{nFe}_{3} \mathrm{O}_{4}$ was dried in a vacuum oven at $60{ }^{\circ} \mathrm{C}$ for $12 \mathrm{~h}$ and stored in a sealed bottle for further use.

Then, the $\mathrm{ClO}_{4}{ }^{-}$-template solution was prepared (Scheme 1(b)). $5 \mathrm{~mL}$ of $0.2 \mathrm{~mol} \mathrm{~L}^{-1}$ EDA ethanol solution and $8 \mathrm{~mL}$ of $0.2 \mathrm{~mol} \mathrm{~L}^{-1}$ GMA ethanol solution were mixed and stirred at room temperature for $30 \mathrm{~min}$, followed by adding $10 \mathrm{~mL}$ of $0.2 \mathrm{~mol} \mathrm{~L}^{-1} \mathrm{KClO}_{4}$ ethanol solution dropwisely, and stirred at room temperature for another $2 \mathrm{~h}$, to obtain the $\mathrm{ClO}_{4}{ }^{-}$-templated functional monomer solution at the concentration of $0.1 \mathrm{~mol} \mathrm{~L}^{-1}$ (calculated based on the $\mathrm{ClO}_{4}{ }^{-}$).

Afterward, $\mathrm{nFe}_{3} \mathrm{O}_{4}$ @IIPs was prepared by dispersive polymerization (Scheme 1(c)). $1.0 \mathrm{~g}$ of $\mathrm{nFe}_{3} \mathrm{O}_{4}$ was dispersed $25 \mathrm{~mL}$ ethanol under ultrasonication, then the above obtained $20 \mathrm{~mL}$ of $\mathrm{ClO}_{4}{ }^{-}$-template solution, and $10 \mathrm{~mL} 0.2 \mathrm{~mol} \mathrm{~L}^{-1}$ of St ethanol solution, and $0.5 \mathrm{~g}$ DVB were added accordingly. Finally, $0.1 \mathrm{~g}$ of benzoyl peroxide (BPO) dissolved in $25 \mathrm{~mL}$ ethanol was added dropwisely under vigorously stirring. The mixture was continuously reacted at $80{ }^{\circ} \mathrm{C}$ for $3 \mathrm{~h}$. The template ion, $\mathrm{ClO}_{4}{ }^{-}$, was cleaned with $0.5 \mathrm{~mol} \mathrm{~L}^{-1} \mathrm{NaOH}$ ethanol solution for several times under ultrasound until $\mathrm{ClO}_{4}{ }^{-}$could not be detected by photometric method. ${ }^{25}$ Then protonated by 0.5 mol L ${ }^{-1}$ HAc ethanol solution to obtain the final $\mathrm{nFe}_{3} \mathrm{O}_{4} @ I I P$, named as $\mathrm{nFe}_{3} \mathrm{O}_{4} @ I I P-D 0.5-G 8$. The as-prepared $\mathrm{nFe}_{3} \mathrm{O}_{4} @$ @IP-D0.5-G8 were washed with water three times, dried in a vacuum oven at $60{ }^{\circ} \mathrm{C}$ and stored in a sealed bottle for further use.

Other 3 kinds of $\mathrm{nFe}_{3} \mathrm{O}_{4}$ @IIPs (no. 1, 3, and 4) were synthesized with different usage amount of DVB at $0 \mathrm{~g}, 1 \mathrm{~g}$, and $2 \mathrm{~g}$, respectively, listed in Table 1 . In parallel, the non-imprinted magnetic polymer $\left(\mathrm{nFe}_{3} \mathrm{O}_{4} @\right.$ @IP-D0.5-G8, no. 5) was synthesized almost the same procedures described above without the addition of the templates.

\subsection{Characterization}

The morphology and dimensions of as-prepared $\mathrm{nFe}_{3} \mathrm{O}_{4} @$ IIPs were obtained on a Hitachi $\mathrm{H}-7650$ transmission electron microscopy (TEM) (Hitachi, Japan) at an accelerating voltage of $75 \mathrm{kV}$. The magnetic properties of magnetic particles were measured using a vibrating sample magnetometer (VSM, Lake Shore 7410). Powder X-ray diffraction (XRD) patterns were collected on an X-ray diffractometer (Bruker D8 Advance) with $\mathrm{CuK} \alpha$ radiation at $\lambda=0.154 \mathrm{~nm}$ operating at $40 \mathrm{kV}$ and $40 \mathrm{~mA}$. The content of $\mathrm{Fe}_{3} \mathrm{O}_{4}$ in each of $\mathrm{nFe}_{3} \mathrm{O}_{4}$ @IIPs was calculated from the amount of leached $\mathrm{Fe}$, which was measured by using a spectrophotometer (722, Shanghai, China) according to the 

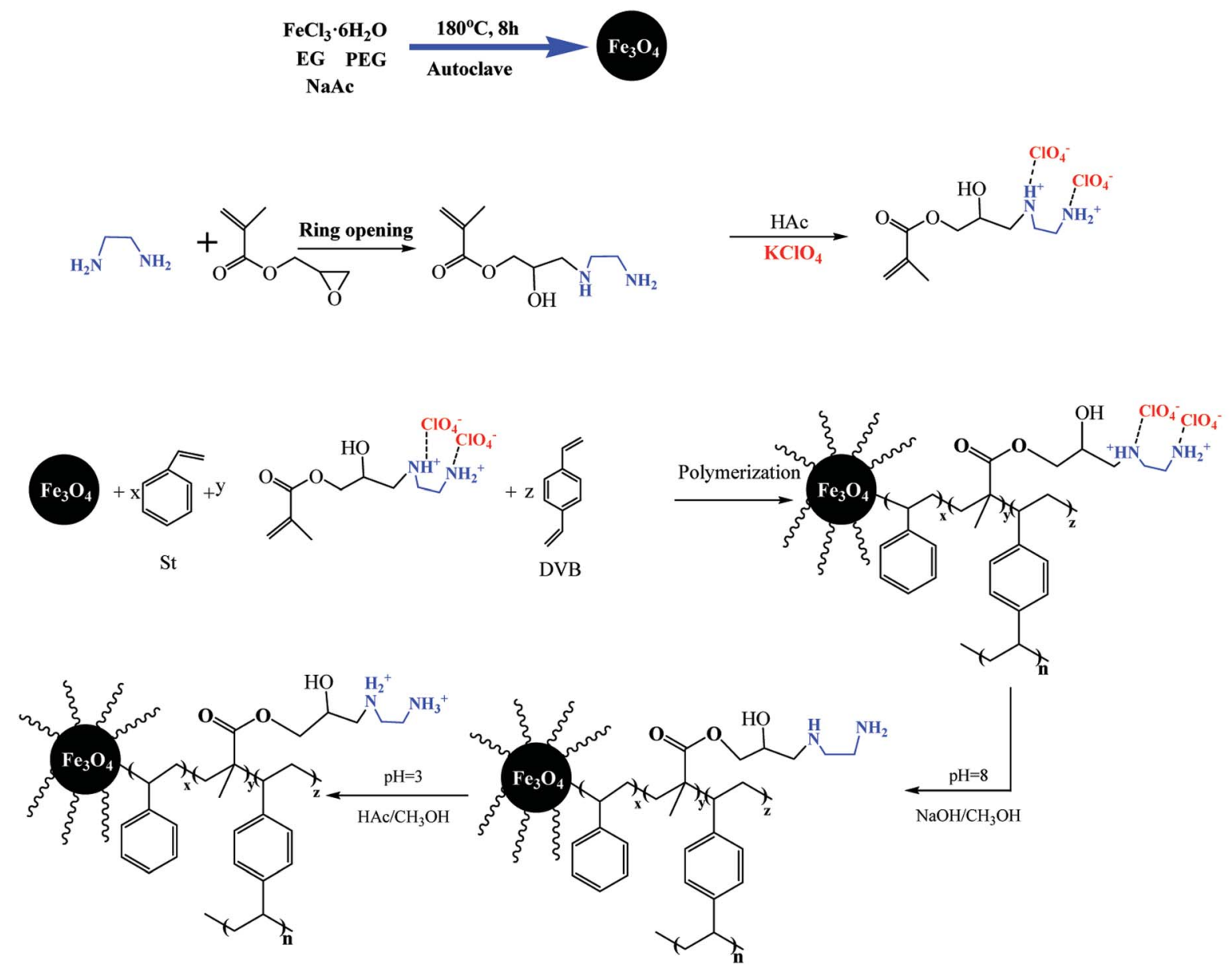

Scheme 1 Schematic procedure of preparation of $\mathrm{nFe}_{3} \mathrm{O}_{4} \mathrm{Q}$ IIP

standard colorimetric method ${ }^{26}$ after digesting $\mathrm{nFe}_{3} \mathrm{O}_{4} @$ @IIPs in $12 \mathrm{~mol} \mathrm{~L}^{-1} \mathrm{HCl}$ solution. The elementary analysis results of the nitrogen contents in $\mathrm{nFe}_{3} \mathrm{O}_{4} @$ @IIP were measured using an elementary analysis (EA, Thermo Fisher Flash-1112). Fourier Transform Infrared spectrometer (FTIR, Thermo Nicolet, USA) were applied for characterization.

\subsection{Adsorption experiments}

Batch adsorption experiments were carried out in $150 \mathrm{~mL}$ stoppered flasks, each of which contained $25 \mathrm{~mL}$ of $\mathrm{KClO}_{4}$ solution. A $20 \mathrm{mg}$ amount of adsorbents was added into each flask and shaken at $180 \mathrm{rpm}$ in a thermostatic shaker. The solution $\mathrm{pH}$ was adjusted by $0.1 \mathrm{~mol} \mathrm{~L}^{-1} \mathrm{HCl}$ or $0.1 \mathrm{~mol} \mathrm{~L}^{-1}$ $\mathrm{NaOH}$ solution. The $\mathrm{KClO}_{4}$ concentration in the supernatant was measured by colorimetric method. ${ }^{25}$ According to the $\mathrm{ClO}_{4}{ }^{-}$ concentrations before and after adsorption, the equilibrium adsorption capacity $\left(q, \mathrm{mg} \mathrm{\textrm {g } ^ { - 1 }}\right)$ of $\mathrm{ClO}_{4}^{-}$bound to the $\mathrm{nFe}_{3^{-}}$ $\mathrm{O}_{4}$ @IIP is calculated using eqn (1): ${ }^{27}$

$$
q=\frac{\left(C_{0}-C_{\mathrm{e}}\right) V}{m}
$$

where $C_{0}$ and $C_{\mathrm{e}}$ represent the initial solution concentration and the equilibrium concentration of $\mathrm{ClO}_{4}{ }^{-}\left(\mathrm{mg} \mathrm{L}^{-1}\right), V$ is the

Table 1 Content of $\mathrm{Fe}_{3} \mathrm{O}_{4}, \mathrm{~N}$, saturation moments and average diameter of $\mathrm{nFe}_{3} \mathrm{O}_{4}$ @llP

\begin{tabular}{|c|c|c|c|c|c|}
\hline 1 & $\mathrm{nFe}_{3} \mathrm{O}_{4} @$ IIP-D0-G8 & 41.5 & 7.82 & 42.8 & 200 \\
\hline 3 & $\mathrm{nFe}_{3} \mathrm{O}_{4} @$ IIP-D1-G8 & 37.6 & 7.22 & 38.7 & 500 \\
\hline 4 & $\mathrm{nFe}_{3} \mathrm{O}_{4} @$ IIP-D2-G8 & 35.4 & 7.08 & 35.6 & $400-800$ \\
\hline 5 & $\mathrm{nFe}_{3} \mathrm{O}_{4} @$ NIP-D0.5-G8 & 39.8 & 7.38 & 40.8 & $200-600$ \\
\hline
\end{tabular}




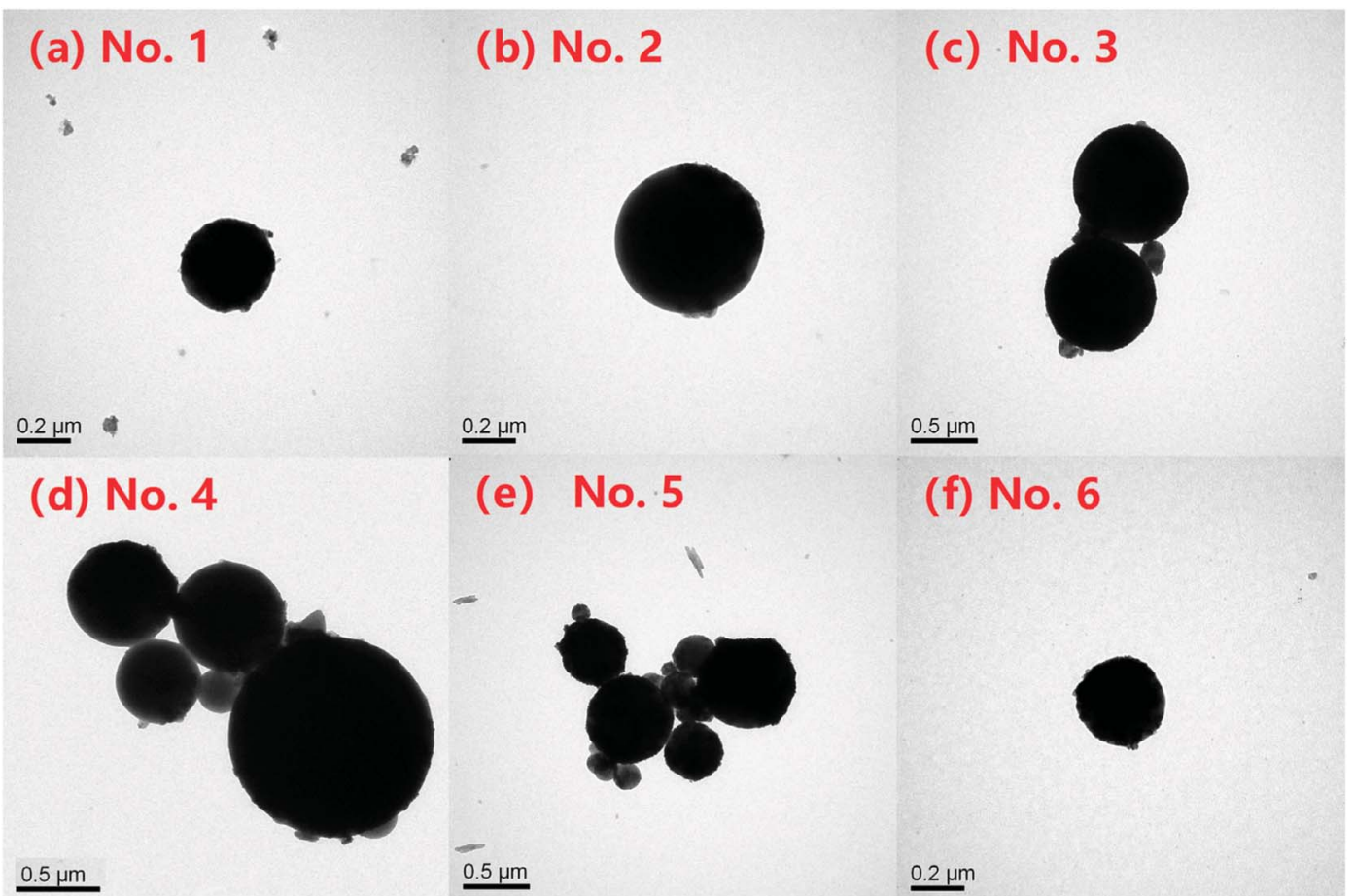

Fig. 1 TEM images of (a) no. 1 nFe $\mathrm{O}_{4}$ @lIP-D0-G8; (b) no. 2 nFe $3 \mathrm{O}_{4}$ @lIP-D0.5-G8; (c) no. 3 nFe $3 \mathrm{O}_{4}$ (allP-D1-G8; (d) no. 4 nFe 3 O 4 (lIP-D2-G8; (e) no. $5 \mathrm{nFe}_{3} \mathrm{O}_{4}$ (aNIP-D0.5-G8; (f) no. $6 \mathrm{nFe}_{3} \mathrm{O}_{4}$.

volume of the $\mathrm{ClO}_{4}{ }^{-}$solution $(\mathrm{mL}), m$ is the adsorbent dosage $(\mathrm{mg})$, the same hereinafter.

To investigate the effect of $\mathrm{pH}, 25 \mathrm{~mL}$ of $100 \mathrm{mg} \mathrm{L}^{-1} \mathrm{ClO}_{4}{ }^{-}$ with $\mathrm{pH}$ ranging from 2.0 to 10.0 were mixed with $20 \mathrm{mg}$ of magnetic adsorbents for $1 \mathrm{~h}$ at $308 \mathrm{~K}$, respectively. In the kinetic experiments, the $\mathrm{nFe}_{3} \mathrm{O}_{4} @$ @IIPs was also investigated with contacting time ranging from 1 to $180 \mathrm{~min}$. The pseudo-first-order model (eqn (2)), ${ }^{27}$ pseudo-second-order model (eqn (3)), ${ }^{27,28}$ and intraparticle diffusion model (eqn (4)), ${ }^{27}$ were used to fit the experimental data.

$$
\begin{gathered}
\log \left(q_{\mathrm{e}}-q_{t}\right)=\log q_{\mathrm{e}}-\left(\frac{k_{1}}{2.303}\right) t \\
\frac{t}{q_{t}}=\frac{1}{k_{2} q_{\mathrm{e}}^{2}}+\left(\frac{1}{q_{\mathrm{e}}}\right) t \\
q_{t}=k_{\mathrm{id}} t^{1 / 2}+C
\end{gathered}
$$

where, $q_{\mathrm{e}}$ and $q_{t}$ are the adsorption capacities at equilibrium and at time $t\left(\mathrm{mg} \mathrm{g}^{-1}\right)$, respectively. $k_{1}\left(\mathrm{~min}^{-1}\right), \quad k_{2}(\mathrm{~g}$ $\left.\left(\mathrm{mg}^{-1} \min ^{-1}\right)\right)$ are the adsorption rate constants, $k_{\mathrm{id}}$ is the intraparticle diffusion rate constant $\left(\mathrm{mg}\left(\mathrm{g}^{-1} \mathrm{~min}^{-1 / 2}\right)\right), C$ is the intercept $\left(\mathrm{mg} \mathrm{g}^{-1}\right)$.

The adsorption isotherm studies were investigated with $\mathrm{ClO}_{4}{ }^{-}$initial concentration ranging from 0 to $500 \mathrm{mg} \mathrm{L}^{-1}$ at 308 $\mathrm{K}$ for $3 \mathrm{~h}$. Two adsorption isotherms, Langmuir model (eqn (5)) ${ }^{27,29}$ and Freundlich model (eqn (6)) were applied to analyze the adsorption data ${ }^{27,29}$

$$
\frac{C_{\mathrm{e}}}{q_{\mathrm{e}}}=\frac{1}{K_{\mathrm{L}} q_{\mathrm{m}}}+\frac{C_{\mathrm{e}}}{q_{\mathrm{m}}}
$$

$$
\log q_{\mathrm{e}}=\log K_{\mathrm{F}}+(1 / n) \log C_{\mathrm{e}}
$$

where $q_{\mathrm{m}}$ and $K_{\mathrm{L}}$ are the Langmuir constants related to the maximum adsorption capacity and apparent heat change, respectively, while $K_{\mathrm{F}}$ is a Freundlich constant related to adsorption capacity and $1 / n$ is a Freundlich constant related to the adsorption intensity.

\subsection{Selectivity}

Common ions with similar ionic radii of $\mathrm{ClO}_{4}{ }^{-}$, such as $\mathrm{CrO}_{4}{ }^{2-}$, $\mathrm{H}_{2} \mathrm{PO}_{4}{ }^{-}, \mathrm{NO}_{3}{ }^{-}, \mathrm{HSO}_{4}{ }^{-}, \mathrm{MnO}_{4}{ }^{-}$and $\mathrm{I}^{-}$were chosen to evaluate the selectivity of the $\mathrm{nFe}_{3} \mathrm{O}_{4} @$ @IIP and $\mathrm{nFe}_{3} \mathrm{O}_{4} @ \mathrm{NIP}$ and individually dispersed into $25 \mathrm{~mL}$ of $100 \mathrm{mg} \mathrm{L}^{-1} \mathrm{ClO}_{4}{ }^{-}$. The mixtures were shaken for $3 \mathrm{~h}$ at $308 \mathrm{~K}$, and the concentrations of $\mathrm{ClO}_{4}{ }^{-}$and other ions in the supernatants were analyzed by ion chromatography (IC). The IL analysis was performed on a Thermo Scientific Dionex DX-500 with a gradient pump (Dionex GP50) at a flow of $0.25 \mathrm{~mL} \mathrm{~min}^{-1}$, an autosampler (Dionex AS50) with $1000 \mu$ L-injection loop, a column thermostat set at $30{ }^{\circ} \mathrm{C}$ (Dionex Ultimate 3000 TCC-3000), an eluent generator (Dionex RFC-30) equipped with an eluent generator cartridge (Dionex EGC-III KOH), continuously regenerated trap column (Dionex CR-ATC), and a conductivity detector (Dionex CD-25). Separation was performed on a Dionex IonPac AS20 column and guard column-set. Columns and suppressor were in the $2 \mathrm{~mm}$ format, and data acquisition and evaluation were done using the Dionex Chromeleon 6.70 chromatography software. The eluent ( $35 \mathrm{mmol} \mathrm{L}^{-1} \mathrm{KOH}$ ) was produced electrolytically in situ. For eluent suppression prior to conductivity detection, a Dionex AERS 500 was used at a current setting of 22 
mA. Samples were injected with volumes of $200 \mu \mathrm{L}$. The adsorptive amounts of $\mathrm{ClO}_{4}{ }^{-}$and other ions to $\mathrm{nFe}_{3} \mathrm{O}_{4} @$ @IIPs and $\mathrm{nFe}_{3} \mathrm{O}_{4} @ \mathrm{NIP}$ were then compared.

The specific recognition properties of $\mathrm{nFe}_{3} \mathrm{O}_{4} @$ @IIPs are evaluated by imprinting factor $(\alpha)$, defined as eqn (7), and selectivity factor $(\beta)$ defined as eqn (8): ${ }^{30}$

$$
\alpha=\frac{q_{\mathrm{IIP}}}{q_{\mathrm{NIP}}}
$$

where $q_{\mathrm{IIP}}$ and $q_{\mathrm{NIP}}$ are the adsorption capacity of the template or the analogue on IIP and NIP, respectively.

$$
\beta=\frac{\alpha_{\text {tem }}}{\alpha_{\text {ana }}}
$$

where, $\alpha_{\text {tem }}$ and $\alpha_{\text {ana }}$ are the imprinting factor toward the template ion and analogue, respectively.

\section{Results and discussion}

\subsection{Characterization of $\mathrm{nFe}_{3} \mathrm{O}_{4} @$ IIPs}

The TEM spectra of the $\mathrm{nFe}_{3} \mathrm{O}_{4}$ @IIPs were shown in Fig. 1 . It revealed that the diameter of $\mathrm{nFe}_{3} \mathrm{O}_{4}$ @IIPs increased from $200 \mathrm{~nm}$ to $800 \mathrm{~nm}$ with the increasing of the usage amount of DVB (Fig. 1(a)-(d)) during the co-polymerization procedure. It might be due to the fact that the more DVB used, the more cross-linking of polymer layer grafted onto the $\mathrm{nFe}_{3} \mathrm{O}_{4}$ magnetic core, which leading an increasing of the average diameter. When the usage amount of the DVB reached $1 \mathrm{~g}$ (Fig. 1(d)), the particle size distribution became not uniform and varied from $400 \mathrm{~nm}$ to $800 \mathrm{~nm}$. The TEM spectra of the $\mathrm{nFe}_{3} \mathrm{O}_{4} @ N I P-D 0.5-$ G8 (Fig. 1(e)) and $\mathrm{nFe}_{3} \mathrm{O}_{4}$ (Fig. 1(f)) were also investigated, and showed that the particle size distribution of the non-imprinted magnetic polymer was not as uniform as the imprinted analogues, ranging from $200-600 \mathrm{~nm}$, while the bare $\mathrm{nFe}_{3} \mathrm{O}_{4}$ microspheres had a multidispersed spherical shape with a rough surface, with an average diameter of around $200 \mathrm{~nm}$. The average diameter of the 4 kinds of $\mathrm{nFe}_{3} \mathrm{O}_{4}$ @IIPs and the $\mathrm{nFe}{ }_{3} \mathrm{O}_{4} @ N I P$, as well as the bare $\mathrm{nFe}_{3} \mathrm{O}_{4}$ was summarized in Table 1.

The XRD of $\mathrm{nFe}_{3} \mathrm{O}_{4} @$ @IIPs was shown in Fig. 2. It indicated that $\mathrm{nFe}_{3} \mathrm{O}_{4} @ I I P s$ had retained the spinel structure of $\mathrm{Fe}_{3} \mathrm{O}_{4}$, in which the identical peaks for $\mathrm{Fe}_{3} \mathrm{O}_{4}$ located at $30.1^{\circ}, 35.5^{\circ}, 43.1^{\circ}$, $53.4^{\circ}, 57.0^{\circ}$ and $62.6^{\circ}$, corresponding to their indices (220), (311), (400), (422), (511) and (400) appeared..$^{31}$ The diffraction peaks of the $\mathrm{nFe}_{3} \mathrm{O}_{4}$ @IIPs were slightly more broaden than that of pure $\mathrm{nFe}_{3} \mathrm{O}_{4}$. The FWHM of the peak at $35.5^{\circ}$ (311) was taken as an example, increasing from $0.59933\left(\mathrm{a}, \mathrm{nFe}_{3} \mathrm{O}_{4}\right)$ to 0.64522 (b, $\left.\mathrm{nFe}_{3} \mathrm{O}_{4} @ I I P-D 0-G 8\right) ; 0.65178$ (c, $\mathrm{nFe}_{3} \mathrm{O}_{4}$ @IIP-D0.5-G8); 0.69442 (d, nFe $\mathrm{O}_{4} @$ @IIP-D1-G8); and 0.72884 (e, nFe $\mathrm{O}_{4} @$ @IIPD2-G8), which indicated that the $\mathrm{nFe}_{3} \mathrm{O}_{4} @$ IIPs have smaller scale, which were consistent to the TEM results and might be favorable for the rapid adsorption and the increase of adsorption capacity. ${ }^{31}$

The paramagnetic property of the $\mathrm{nFe}_{3} \mathrm{O}_{4} @$ @IIPs was verified by the magnetization curve measured by VSM (Fig. 3). The saturation moments obtained from the hysteresis loops of were summarized in Table 1, and found to be at 35.6-42.8 emu $\mathrm{g}^{-1}$,

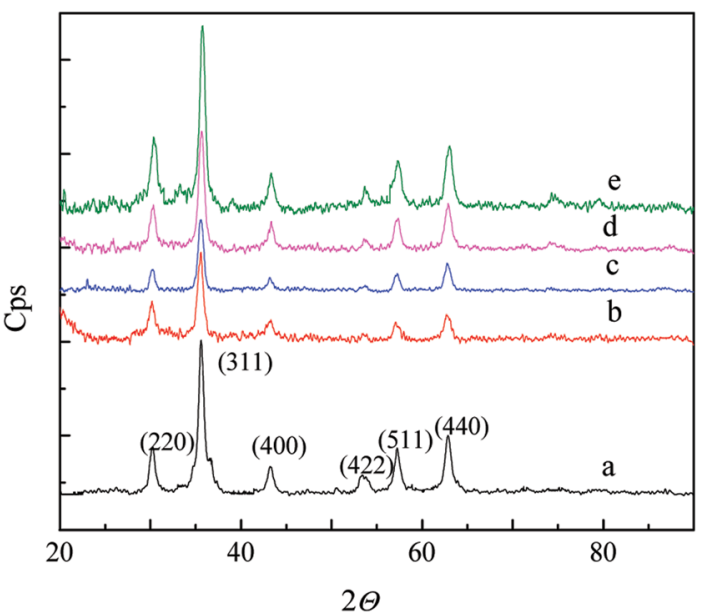

Fig. 2 The XRD of (a) $\mathrm{nFe}_{3} \mathrm{O}_{4}$; (b) $\mathrm{nFe}_{3} \mathrm{O}_{4}$ (allP-DO-G8; (c) $\mathrm{nFe}_{3} \mathrm{O}_{4}$ (allPD0.5-G8; (d) nFe $\mathrm{O}_{4}$ (allP-D1-G8; (e) nFe $\mathrm{O}_{4}$ (alIP-D2-G8.

varying with the usage amount of DVB. The $\mathrm{nFe}_{3} \mathrm{O}_{4} @$ @IIPs was expected to respond well to magnetic field without any permanent magnetization, therefore making the solid and liquid phases separate easily. For comparing, the saturation moments, $\mathrm{Fe}_{3} \mathrm{O}_{4}$ contents and nitrogen contents of all the prepared $\mathrm{nFe}_{3} \mathrm{O}_{4} @$ @IIPs and $\mathrm{nFe}_{3} \mathrm{O}_{4} @ \mathrm{NIP}$ were also investigated. Results were shown in Table 1. The $\mathrm{Fe}_{3} \mathrm{O}_{4}$ content of the $\mathrm{nFe}_{3} \mathrm{O}_{4} @$ @IIP decreased from $41.5 \%$ to $35.4 \%$ (no. 1 to 4 in Table 1 ) with the usage amount of the DVB increased during the preparation procedure. The results were consistent to the VSM results of the $\mathrm{nFe}_{3} \mathrm{O}_{4}$ @IIPs. With the increasing of the usage amount of the DVB, the nonmagnetic sensitive polymer shell grafted onto the surface of the $\mathrm{nFe}_{3} \mathrm{O}_{4}$ increased, leading the $\mathrm{Fe}_{3} \mathrm{O}_{4}$ content of the $\mathrm{nFe}_{3} \mathrm{O}_{4}$ @IIPs decreased as well as the saturation moments decreased. The nitrogen content of the $\mathrm{nFe}_{3} \mathrm{O}_{4}$ @IIPs decreased from 7.82 to $7.08 \mathrm{mmol} \mathrm{g}^{-1}$, with the usage amount of the DVB. With fixed usage amount of the GMA, the increasing the usage amount the DVB (no. 1 to 4 in Table 1) would cause a decrease of

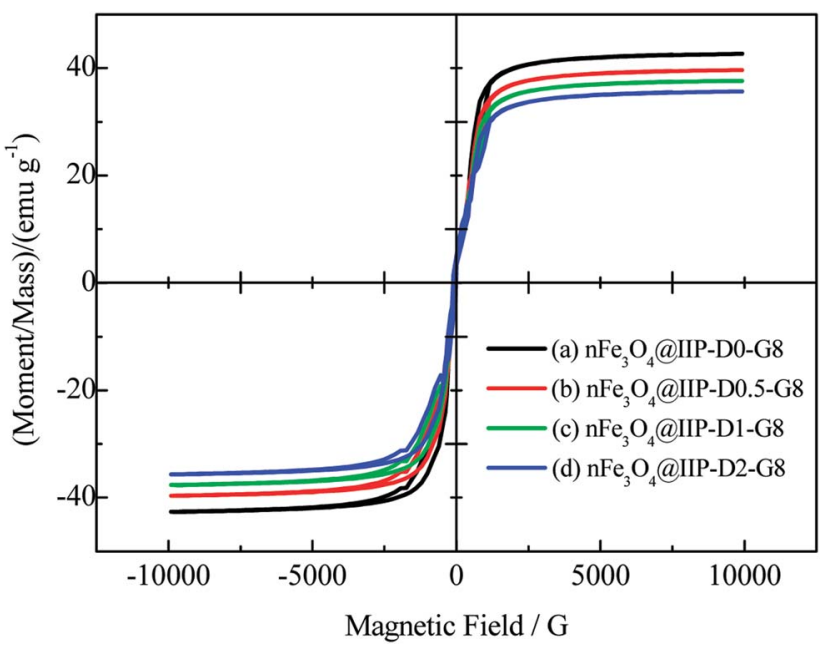

Fig. 3 The VSM of (a) $\mathrm{nFe}_{3} \mathrm{O}_{4}$ (alIP-D0-G8; (b) $\mathrm{nFe} \mathrm{O}_{3}$ (alIP-D0.5-G8; (c) $\mathrm{nFe}_{3} \mathrm{O}_{4}$ (lIP-D1-G8; (d) $\mathrm{nFe}_{3} \mathrm{O}_{4}$ (allP-D2-G8. 
the percentage of the GMA groups in polymer shell, thus leading a slight decrease of amino-groups via ring-opening reaction, and eventually leading a decrease of the nitrogen percentage (Table 1).

\subsection{Effect of solution $\mathrm{pH}$ and the presumed adsorption mechanism}

The adsorption capacity of the $\mathrm{nFe}_{3} \mathrm{O}_{4} @$ NIP-D0.5-G8 and the $\mathrm{nFe}_{3} \mathrm{O}_{4} @$ IIPs were investigated for the $\mathrm{pH}$ values ranging from 1.5 to 7.0. The results were shown in Fig. 4. The adsorption capacity of $\mathrm{nFe}_{3} \mathrm{O}_{4}$ @NIP-D0-G8 to $\mathrm{ClO}_{4}{ }^{-}$was dependent on solution $\mathrm{pH}$ (Fig. 4(a)). With the solution $\mathrm{pH}$ increasing, the adsorption capacities firstly increased with the solution $\mathrm{pH}$ ranging from 1.5 to 3.0, and reached to the maximum at $\mathrm{pH} 3.0$, then decreased. Those of the $\mathrm{nFe}_{3} \mathrm{O}_{4}$ @IIPs were of similar trends. For the 4 kinds of $\mathrm{nFe}_{3} \mathrm{O}_{4} @$ @IIPs obtained with the usage of DVB varied (Fig. 4(b)-(e)), the highest adsorption capacities was obtained for the $\mathrm{nFe}_{3} \mathrm{O}_{4}$ @IIP-D0.5-G8, while the lowest one was the $\mathrm{nFe}_{3} \mathrm{O}_{4}$ @IIP-D2-G8, with almost 2 times of the adsorption capacities as that of $\mathrm{nFe}_{3} \mathrm{O}_{4}$ @NIP-D0-G8. Except $\mathrm{nFe}_{3} \mathrm{O}_{4}$ @IIP-D0-G8, this result was consistent with the nitrogen content of the $\mathrm{nFe}_{3} \mathrm{O}_{4}$ @IIPs. The higher nitrogen content implied the more amino groups anchored on the surface of the $\mathrm{nFe}_{3} \mathrm{O}_{4}$ @IIPs, leading a higher adsorption capacities, which was consistent to the results of the nitrogen percentage of the $\mathrm{nFe}_{3} \mathrm{O}_{4} @$ @IPs, as discussed above and shown in Table 1. Interestingly, the solution $\mathrm{pH}$ affect the adsorption of the $\mathrm{nFe}_{3}$ $\mathrm{O}_{4} @$ IIP-D0-G8 much more significantly than the other $\mathrm{nFe}_{3} \mathrm{O}_{4}$ @IIPs obtained via adding a certain amount of DVB. As shown in Fig. 4(b), with the solution $\mathrm{pH}$ increasing, the adsorption capacities of the $\mathrm{nFe}_{3} \mathrm{O}_{4} @$ IIP-D0-G8 increased sharply and reached to the maximum at $\mathrm{pH} 3.0$, then decreased sharply, as well. However, the adsorption capacities varying of the other $\mathrm{nFe}_{3} \mathrm{O}_{4}$ @IIPs (Fig. 4(c)-(e)) was relatively much milder in the range of $\mathrm{pH}$ value 2-4. This implied that the presence of DVB might be contributed to the stabilization of ion imprinting

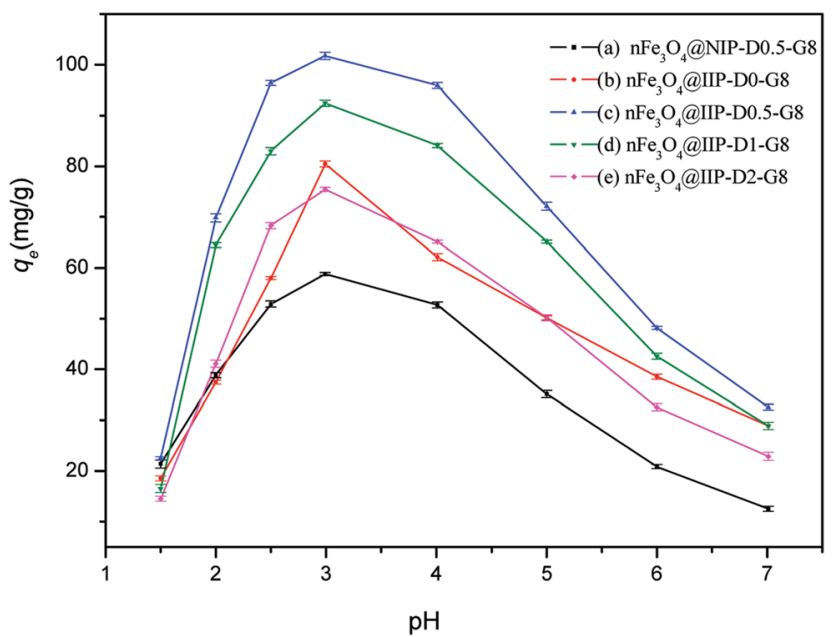

Fig. 4 Effect of solution $\mathrm{pH}$ value on the adsorption of $\mathrm{ClO}_{4}{ }^{-}$by $n \mathrm{ne}_{3} \mathrm{O}_{4}$ @NIP-D-0.5-G8 (a), $\mathrm{nFe}_{3} \mathrm{O}_{4}$ @IIPs (with DVB varied (b)-(e)).

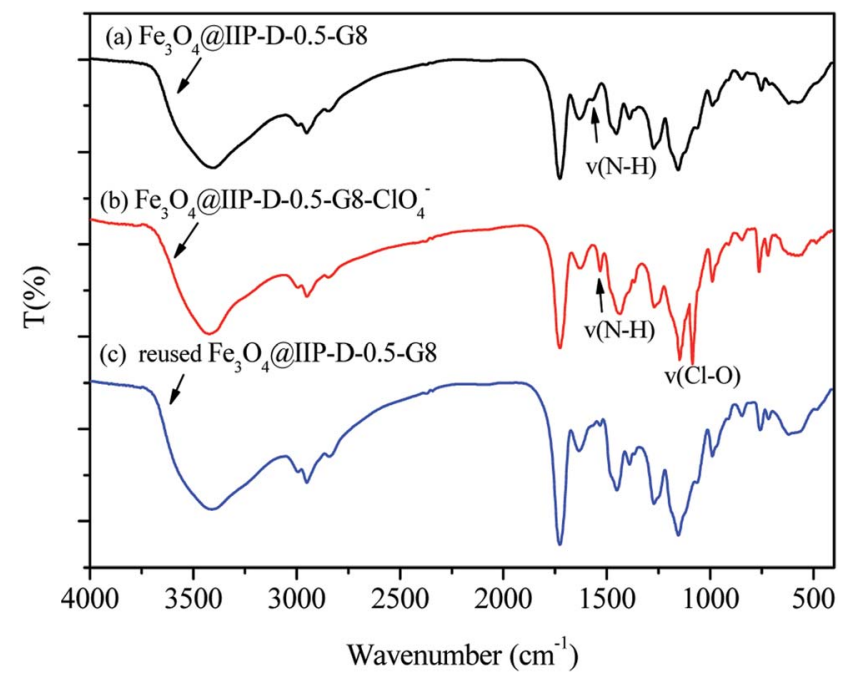

Fig. 5 FTIR of the $\mathrm{nFe}_{3} \mathrm{O}_{4}$ (allP-D-0.5-G8 (a) before, (b) after adsorption of $\mathrm{ClO}_{4}{ }^{-}$and (c) reused.

holes, which would be favorable to the improvement of adsorption capacity and to the stabilization of a wider $\mathrm{pH}$ range.

The FTIR spectra of $\mathrm{nFe}_{3} \mathrm{O}_{4}$ @IIP-D-0.5-G8 before and after adsorption of $\mathrm{ClO}_{4}{ }^{-}$were showed in Fig. 5 and could be used for the confirmation of the adsorption mechanism. As shown in Fig. 5(a), the characteristic band of $\mathrm{Fe}_{3} \mathrm{O}_{4}$ occurred at $\sim 589 \mathrm{~cm}^{-1}$. The broad peak appeared at $\sim 3400 \mathrm{~cm}^{-1}$ and 1635 , $\sim 1568 \mathrm{~cm}^{-1}$ can be assigned to be the stretching and bending vibrations of the $-\mathrm{OH},-\mathrm{NH}_{2}{ }^{+}$and $-\mathrm{NH}_{3}{ }^{+}$groups. The stretching vibration absorptions of $-\mathrm{CH}_{2}$ and $-\mathrm{CH}_{3}$ appeared at $\sim 2924 \mathrm{~cm}^{-1}, \sim 2853 \mathrm{~cm}^{-1}$, while that of $\mathrm{C}=\mathrm{O}$ appeared at $\sim 1630 \mathrm{~cm}^{-1}$. After adsorption (Fig. 5(b)), the characteristic bands at $\sim 1568 \mathrm{~cm}^{-1}$ shifted to $\sim 1530 \mathrm{~cm}^{-1}$ along with the appearance of two new bands at $\sim 1090 \mathrm{~cm}^{-1}$ and $\sim 1145 \mathrm{~cm}^{-1}$. After desorption (Fig. 5(c)), the latter two peaks disappeared, which might be attributed to the stretching vibration of the $\mathrm{ClO}_{4}{ }^{-}$(ref. 32), indicating that the interaction between $-\mathrm{NH}_{2}{ }^{+}$ and $-\mathrm{NH}_{3}{ }^{+}$groups and the $\mathrm{ClO}_{4}{ }^{-}$were realized via the electrostatic interaction.

\section{3. $\quad$ Kinetic studies}

Fig. 6 presented the adsorption kinetics of $\mathrm{ClO}_{4}{ }^{-}$, onto $\mathrm{nFe}_{3}{ }^{-}$ $\mathrm{O}_{4} @$ @IIPs and $\mathrm{nFe}_{3} \mathrm{O}_{4} @$ NIP. As shown in Fig. 6 (left, (a) and (b)), for $\mathrm{nFe}_{3} \mathrm{O}_{4} @ N I P-D-0.5-\mathrm{G} 8$ and $\mathrm{nFe}_{3} \mathrm{O}_{4} @$ IIP-D-0-G8, the adsorption capacity increased gradually and reached equilibrium in nearly $60 \mathrm{~min}$, while for $\mathrm{nFe}_{3} \mathrm{O}_{4} @ I I P-D-0.5-\mathrm{G} 8, \mathrm{nFe}_{3}$ $\mathrm{O}_{4}$ @IIP-D-1-G8 and $\mathrm{nFe}_{3} \mathrm{O}_{4}$ @IIP-D-2-G8 (Fig. 6, left, (c)-(e), respectively), the adsorption capacity increased rapidly, and only 10 min were needed to reach adsorption equilibrium. This revealed that the existing of the $\mathrm{ClO}_{4}{ }^{-}$-template and the presence of DVB for the crosslinking during the preparation process would stabilize the surface imprinting cavities in polymer matrix of the $\mathrm{nFe}_{3} \mathrm{O}_{4} @$ @IIPs and eventually shorten the equilibrium time. The kinetic curves of $\mathrm{nFe}_{3} \mathrm{O}_{4} @ N I P-D-0.5-G 8$ and $\mathrm{nFe}_{3} \mathrm{O}_{4}$ @IIP-D-0-G8, could be divided into three portions, which could be described by intraparticle diffusion model (shown in 

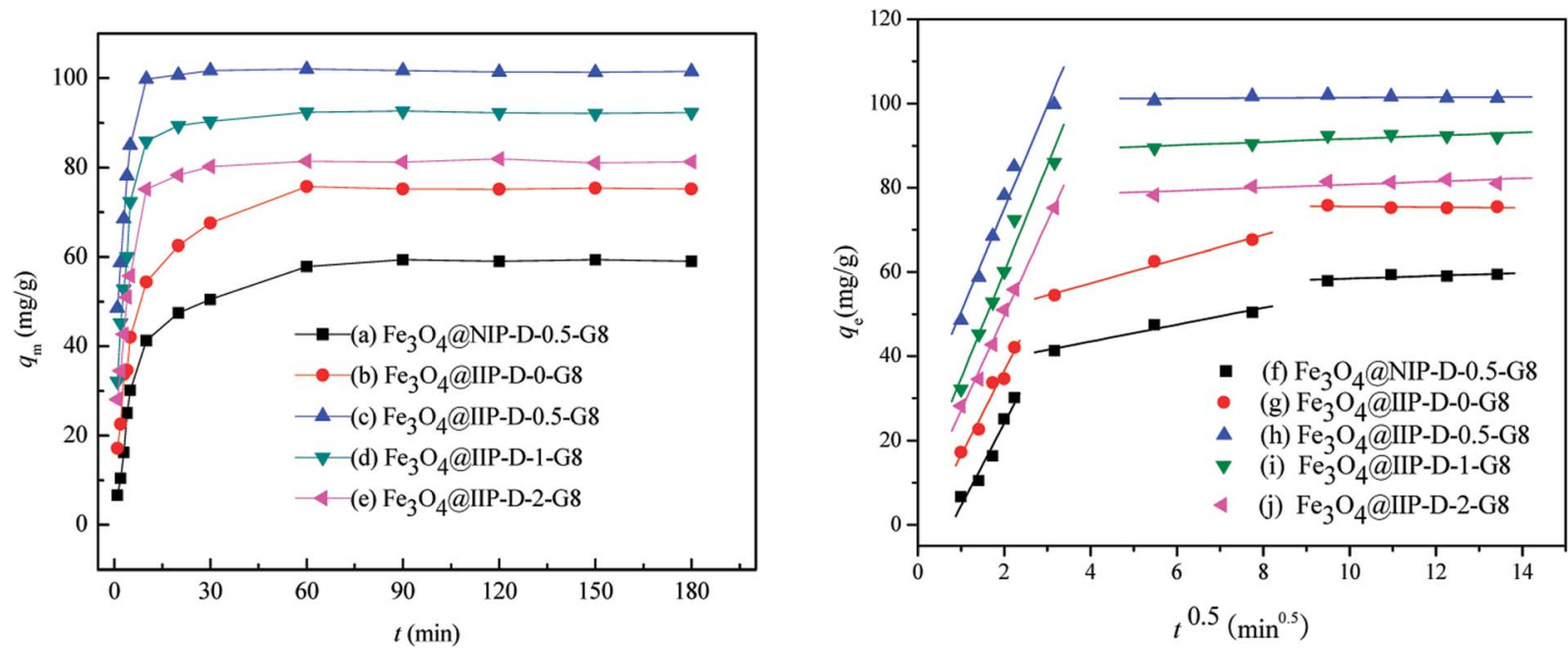

Fig. 6 Effect of adsorption time on the adsorption of $\mathrm{ClO}_{4}^{-}$by $\mathrm{nFe} \mathrm{O}_{4} \mathrm{ONIPs}-\mathrm{D}-0.5-\mathrm{G} 8$ (a), (f), $\mathrm{nFe} \mathrm{O}_{4} \mathrm{Q}$ (IIPs (with DVB varied (b)-(e), (g)-(j)).

Fig. 6, right, (f) and (g)) and indicated that the intra-particle process $^{33}$ might be one of the rate-limiting steps for $\mathrm{ClO}_{4}{ }^{-}$ removal. The kinetic curves of the other $\mathrm{nFe}_{3} \mathrm{O}_{4} @$ @IIPs could only be divided into two portions (Fig. 6, right, (h)-(j)), thus, the intra-particle process might not be involved in the rate-limiting steps. Therefore, in the present case, $\mathrm{ClO}_{4}{ }^{-}$reached the surface imprinting cavities of $\mathrm{nFe}_{3} \mathrm{O}_{4}$ @IIPs easily and took less time to reach adsorption equilibrium, implying that the surface imprinting and uniform structures of $\mathrm{nFe}_{3} \mathrm{O}_{4} @$ @IIPs allowed efficient mass transport, thus overcoming some drawbacks of traditionally non-imprinting materials. The presence of DVB for the crosslinking took an important role for the stabilization of the imprinting cavities of the $\mathrm{nFe}_{3} \mathrm{O}_{4} @$ @IIPs and favorable for the adsorption kinetic processes.

Pseudo-first-order and pseudo-second-order models were used to describe the adsorption kinetic data. The results were shown in ESI, Fig. S1 and S2.\$The correlation coefficient values indicated a better fit of the pseudo-second-order model with the experimental data compared to the pseudo-first-order for all the $\mathrm{nFe}_{3} \mathrm{O}_{4} @$ @IIPs and $\mathrm{nFe}_{3} \mathrm{O}_{4} @$ NIP (Table 2). The calculated $q_{\mathrm{e}}$ values were in agreement with the theoretical ones, and the plots showed good linearity with $R^{2}$ above 0.999 . Therefore, the adsorption behaviors followed the pseudo-second-order model, suggesting a chemisorption process, ${ }^{34}$ including both ion exchange and electrostatic interaction.

\subsection{Adsorption capacities}

The adsorption capacities of $\mathrm{ClO}_{4}{ }^{-}$were investigated for all the $\mathrm{nFe}_{3} \mathrm{O}_{4} @$ @IIPs and $\mathrm{nFe}_{3} \mathrm{O}_{4} @$ @NIP (Fig. 7). Both Langmuir and Freundlich adsorption models were applied for data fitting analysis. The results were shown in ESI, Fig. S3 and S4.\$ The represented parameters using Langmuir and Freundlich adsorption models indicated that the Langmuir model could effectively describe the adsorption data with $R^{2}>0.995$ (Table 3 ), suggesting a better fit of the Langmuir isotherm rather than Freundlich isotherm, which suggested a monolayer adsorption.

As shown in Fig. 7(a) and Table 3, the maximum adsorption capacities of $\mathrm{nFe}_{3} \mathrm{O}_{4} @ \operatorname{IIPs}\left(q_{\mathrm{m}, \mathrm{c}}=76.92-111.1 \mathrm{mg} \mathrm{g}^{-1} ; q_{\mathrm{m}, \mathrm{e}}=\right.$ $\left.75.7-108.9 \mathrm{mg} \mathrm{g}^{-1}\right)$ were much higher than that of $\mathrm{nFe}_{3} \mathrm{O}_{4} @$ @NIPs-D-0.5-G8 $\left(q_{\mathrm{m}, \mathrm{c}}=60.61 \mathrm{mg} \mathrm{g}^{-1} ; q_{\mathrm{m}, \mathrm{e}}=59.0 \mathrm{mg} \mathrm{g}^{-1}\right)$. It can be seen that by using the ion imprinting technology, the adsorptive capacities of the obtained materials $\left(\mathrm{nFe}_{3} \mathrm{O}_{4} @\right.$ @IIPs) to $\mathrm{ClO}_{4}{ }^{-}$can be improved. Although with the usage amount of the crosslinking agent DVB increased, the contents of the protonated amino groups in the $\mathrm{nFe}_{3} \mathrm{O}_{4}$ @IIPs reduced $1.1 \% \sim$ $3.4 \%$ from $\mathrm{nFe}_{3} \mathrm{O}_{4}$ @IIPs-D-0-G8 to $\mathrm{nFe}_{3} \mathrm{O}_{4}$ @IIPs-D-2-G8 (Table 1), the adsorption capacities of the $\mathrm{nFe}_{3} \mathrm{O}_{4} @$ @IIPs did not decrease as expected, but an increase of around $34.6 \%$ for $\mathrm{nFe}_{3} \mathrm{O}_{4} @$ @IIP-D0.5-G8 and 16.2\% for $\mathrm{nFe}_{3} \mathrm{O}_{4} @$ @IIP-D1-G8, were observed (Table 3). And till to the amount of DVB increased to $2.0 \mathrm{~g}$, the decrease of the adsorption capacity at about $4.9 \%$

Table 2 Pseudo-first-order and pseudo-second-order models and constants

\begin{tabular}{|c|c|c|c|c|c|c|c|}
\hline Adsorbents & $q_{\mathrm{e}, \exp }\left(\mathrm{mg} \mathrm{g}^{-1}\right)$ & $k_{1}\left(\min ^{-1}\right)$ & $q_{\mathrm{e}, \mathrm{cal}}\left(\mathrm{mg} \mathrm{g}^{-1}\right)$ & $R^{2}$ & $k_{2}\left(\mathrm{~g}\left(\mathrm{mg}^{-1} \min ^{-1}\right)\right)$ & $q_{\mathrm{e}, \mathrm{cal}}\left(\mathrm{mg} \mathrm{g}^{-1}\right)$ & $R^{2}$ \\
\hline $\mathrm{nFe}_{3} \mathrm{O}_{4} @ I I P-D 0.5-G 8$ & 102 & 0.052 & 7.58 & 0.3553 & 0.0122 & 102 & 0.9997 \\
\hline $\mathrm{nFe}_{3} \mathrm{O}_{4} @ I I P-D 1-G 8$ & 92.7 & 0.735 & 13.7 & 0.532 & 0.0072 & 93.5 & 0.9999 \\
\hline $\mathrm{nFe}_{3} \mathrm{O}_{4} @ I I P-D 2-G 8$ & 81.9 & 0.0619 & 16.14 & 0.6124 & 0.0067 & 82.6 & 0.9999 \\
\hline
\end{tabular}




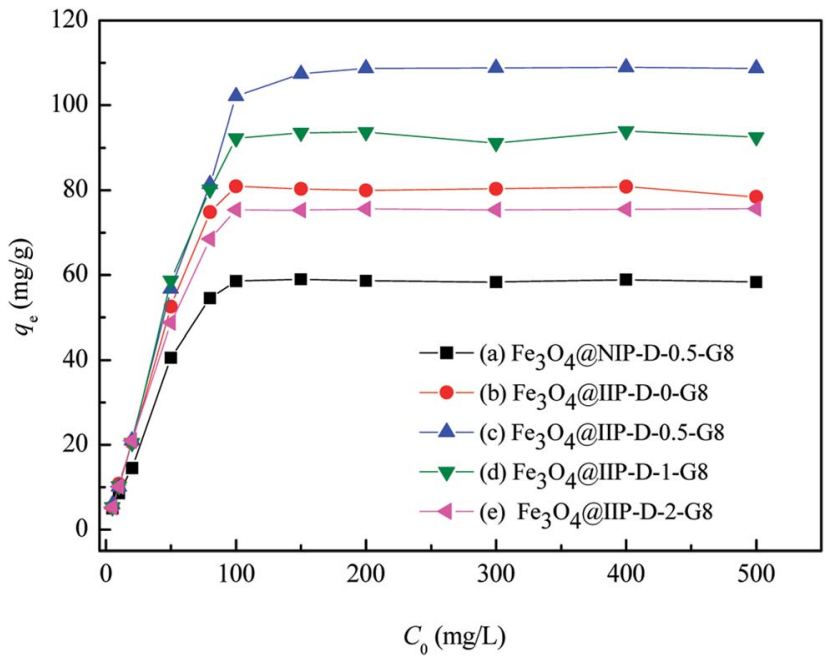

Fig. 7 Adsorption isotherm of $\mathrm{ClO}_{4}{ }^{-}$onto $\mathrm{nFe}_{3} \mathrm{O}_{4}$ @NIPs-D-0.5- $\mathrm{G8}$ (a) and $\mathrm{nFe}_{3} \mathrm{O}_{4}$ (allPs (with DVB varied (b)-(e)).

appeared for $\mathrm{nFe}_{3} \mathrm{O}_{4}$ @IIP-D2-G8 (Table 3). It implied that the usage amount of DVB not only affected the structure of the material in the process of material synthesis, but also played a positive correlation with the adsorption properties of the material at a suitable usage amount. Too much amount of crosslinking agent DVB, $2.0 \mathrm{~g}$ in the present work, might cause the active site of the protonated amino group wrapped inside the polymer chain, thus reducing the adsorption capacity.

\subsection{Adsorption selectivity}

It is of great importance to assess the selective recognition towards the template for a novel imprinted material. Adsorption selectivity is known to be related to the size, shape, and functionality of the template of the imprinted cavities in imprinted materials. ${ }^{16}$ Herein, the selectivity of $\mathrm{nFe}_{3} \mathrm{O}_{4} @$ @IIP-D0.5-G8 and $\mathrm{nFe}_{3} \mathrm{O}_{4}$ @NIP-D0.5-G8 towards $\mathrm{ClO}_{4}{ }^{-}$and some other ions with similar ionic radii, ${ }^{35}$ i.e., $\mathrm{CrO}_{4}{ }^{2-}, \mathrm{H}_{2} \mathrm{PO}_{4}{ }^{-}, \mathrm{NO}_{3}{ }^{-}, \mathrm{HSO}_{4}{ }^{-}, \mathrm{MnO}_{4}{ }^{-}$ and $\mathrm{I}^{-}$at individual concentration of $100 \mathrm{mg} \mathrm{L}^{-1}$ was studied. The imprinting factor $(\alpha)$ of $\mathrm{nFe}_{3} \mathrm{O}_{4} @ I I P-D 0.5-\mathrm{G} 8$ for $\mathrm{ClO}_{4}{ }^{2-}$ was 1.8 , which was much larger than those of the other ions with similar ionic radii (Table 4 ). The high selectivity factors $(\beta)$ of the analogs (5.9-49.4) also exhibited high selectivity of $\mathrm{nFe}_{3}$ $\mathrm{O}_{4} @$ @IIP-D0.5-G8 toward $\mathrm{ClO}_{4}{ }^{-}$. This could be attributed to the fact that in adsorbing process, specific recognition sites respect to template ion (here, i.e., $\mathrm{ClO}_{4}{ }^{-}$) were generated on the surface
Table 4 Imprinting factors $(\alpha)$ and selectivity factors $(\beta)$ of $\mathrm{Fe}_{3} \mathrm{O}_{4} \mathrm{a}$ IIP(St-HPMA-DVB)- $0.5^{a}$

\begin{tabular}{llcccr}
\hline Ion & $\begin{array}{l}\text { Ionic radius } \\
(\mathrm{aq} .) / \mathrm{nm}\end{array}$ & $q_{\mathrm{IIP}}\left(\mathrm{mg} \mathrm{g}^{-1}\right)$ & $q_{\mathrm{NIP}}\left(\mathrm{mg} \mathrm{g}^{-1}\right)$ & $\alpha$ & $\beta$ \\
\hline $\mathrm{ClO}_{4}{ }^{-}$ & 0.240 & 111.1 & 60.6 & 1.8 & \\
$\mathrm{CrO}_{4}{ }^{2-}$ & 0.240 & 28.5 & 122.5 & 0.2 & 7.7 \\
$\mathrm{H}_{2} \mathrm{PO}_{4}{ }^{-}$ & 0.238 & 22.1 & 72.5 & 0.3 & 5.9 \\
$\mathrm{NO}_{3}{ }^{-}$ & 0.200 & 2.5 & 68.6 & 0.0 & 49.4 \\
$\mathrm{HSO}_{4}{ }^{-}$ & 0.230 & 6.5 & 62.8 & 0.1 & 17.4 \\
$\mathrm{MnO}_{4}{ }^{-}$ & 0.240 & 7.6 & 60.8 & 0.1 & 14.4 \\
$\mathrm{I}^{-}$ & 0.285 & 2.8 & 42.3 & 0.1 & 27.2
\end{tabular}

${ }^{a} q_{\mathrm{IIP}}$ : Adsorption capacity of $\mathrm{Fe}_{3} \mathrm{O}_{4} @ \mathrm{IIP}(\mathrm{St}-\mathrm{HPMA}-\mathrm{DVB})-0.5 ; q_{\mathrm{NIP}}$ : adsorption capacity of $\mathrm{Fe}_{3} \mathrm{O}_{4} @ \mathrm{NIP}(\mathrm{St}-\mathrm{HPMA}-\mathrm{DVB})-0.5 ; \alpha$ : imprinting factor; $\beta$ : the selectivity factor.

of $\mathrm{nFe}_{3} \mathrm{O}_{4} @$ IIP-D0.5-G8, thus $\mathrm{ClO}_{4}{ }^{-}$was strongly bound to the specific binding sites. As the competitive ions, the recognition sites of the imprinting cavities were not complementary to them, so it had less chance to be adsorbed on the $\mathrm{nFe}_{3} \mathrm{O}_{4} @$ @IIPD0.5-G8. In contrast, the $\mathrm{nFe}_{3} \mathrm{O}_{4} @$ NIP-D0.5-G8 adsorbed template much less than that of $\mathrm{nFe}_{3} \mathrm{O}_{4}$ @IIP-D0.5-G8 since $\mathrm{nFe}_{3} \mathrm{O}_{4} @ N I P-D 0.5-\mathrm{G} 8$ had not generated specific recognition sites due to the absence of template ion.

\subsection{Reusability investigation}

The reusable of the $\mathrm{Fe}_{3} \mathrm{O}_{4} @$ @IIPs was evaluated by comparing the adsorption efficiency. The $\mathrm{ClO}_{4}{ }^{-}$loaded $\mathrm{Fe}_{3} \mathrm{O}_{4}$ @IIPs was extracted with $0.5 \mathrm{~mol} \mathrm{~L}^{-1}$ methanol/NaOH solution for $10 \mathrm{~min}$ twice, and then for adsorption to get the adsorption efficiency. Table 5 listed the reusability of $\mathrm{Fe}_{3} \mathrm{O}_{4}$ @IIPs for $\mathrm{ClO}_{4}{ }^{-}$. The results indicated that $\mathrm{nFe}_{3} \mathrm{O}_{4}$ @IIP-D0.5-G8 and $\mathrm{nFe}_{3} \mathrm{O}_{4}$ @IIPD1-G8 could be used for at least five cycles with a loss of less than $5 \%$ upon recovery on average, while desorption efficiencies decreased to $78.8-80.6 \%$, and the re-adsorption capacities decreased to 43.4-45.5\%, for $\mathrm{nFe}_{3} \mathrm{O}_{4} @$ @IP-D0.5-G8, $\mathrm{nFe}_{3} \mathrm{O}_{4}$ @IIP-D0-G8 and $\mathrm{nFe}_{3} \mathrm{O}_{4} @$ @IP-D2-G8, which further implied that the usage amount of DVB played an important role for the stabilization of the active site of the protonated amino group and the imprinting cavities of the $\mathrm{nFe}_{3} \mathrm{O}_{4} @$ @IIPs when the usage amount at $0.5-1 \mathrm{~g}$ during the preparation procedure.

\subsection{Adsorption comparison}

The adsorption capacities of $\mathrm{nFe}_{3} \mathrm{O}_{4} @$ IIPs and $\mathrm{nFe}_{3} \mathrm{O}_{4} @ \mathrm{NIP}$ compared with other adsorbents examined for the removal of

Table 3 Langmuir and Freundlich isotherms and constants of $\mathrm{ClO}_{4}{ }^{-}$adsorption

\begin{tabular}{|c|c|c|c|c|c|c|c|}
\hline \multirow[b]{2}{*}{ Adsorbents } & \multirow[b]{2}{*}{$q_{\mathrm{m}, \mathrm{e}}\left(\mathrm{mg} \mathrm{g}^{-1}\right)$} & \multicolumn{3}{|c|}{ Langmuir isotherm } & \multicolumn{3}{|c|}{ Freundlich isotherm } \\
\hline & & $K_{\mathrm{L}}\left(\mathrm{L} \mathrm{mg}^{-1}\right)$ & $q_{\mathrm{m}, \mathrm{c}}\left(\mathrm{mg} \mathrm{g}^{-1}\right)$ & $R^{2}$ & $K_{\mathrm{F}}$ & $1 / n$ & $R^{2}$ \\
\hline $\mathrm{nFe}_{3} \mathrm{O}_{4} @ I I P-D 0-G 8$ & 80.9 & 0.1105 & 83.33 & 0.9989 & 2.976 & 0.3827 & 0.7725 \\
\hline $\mathrm{nFe}_{3} \mathrm{O}_{4} @ \mathrm{IIP}-\mathrm{D} 0.5-\mathrm{G} 8$ & 108.9 & 0.1445 & 111.1 & 0.9987 & 3.269 & 0.4045 & 0.7854 \\
\hline $\mathrm{nFe}_{3} \mathrm{O}_{4} @ I I P-D 1-G 8$ & 94.0 & 0.1537 & 95.24 & 0.9986 & 3.158 & 0.3852 & 0.694 \\
\hline $\mathrm{nFe}_{3} \mathrm{O}_{4} @ I I P-D 2-G 8$ & 75.7 & 0.1593 & 76.92 & 0.9994 & 2.825 & 0.3915 & 0.7986 \\
\hline $\mathrm{nFe}_{3} \mathrm{O}_{4} @ \mathrm{NIP}-\mathrm{D0.5}-\mathrm{G} 8$ & 59.0 & 0.0978 & 60.61 & 0.9977 & 2.349 & 0.4146 & 0.8310 \\
\hline
\end{tabular}


Table 5 Reusability of $\mathrm{Fe}_{3} \mathrm{O}_{4}$ (allP(St-HPMA-DVB) for $\mathrm{ClO}_{4}{ }^{-}$

\begin{tabular}{|c|c|c|c|c|c|c|}
\hline Adsorbent & Reusability $^{a}(\%)$ & Run 1 & Run 2 & Run 3 & Run 4 & Run 5 \\
\hline \multirow[t]{2}{*}{$\mathrm{nFe}_{3} \mathrm{O}_{4} @$ @IIP-D0-G8 } & Des & 95.1 & 90.6 & 89.0 & 82.4 & 80.6 \\
\hline & Ads & 70.3 & 68.8 & 57.9 & 48.8 & 45.5 \\
\hline \multirow[t]{2}{*}{$\mathrm{nFe}_{3} \mathrm{O}_{4} @ \mathrm{IIP}-\mathrm{D} 0.5-\mathrm{G} 8$} & Des & 95.3 & 90.1 & 88.0 & 82.0 & 80.4 \\
\hline & Ads & 72.3 & 69.7 & 56.4 & 48.6 & 44.5 \\
\hline \multirow[t]{2}{*}{$\mathrm{nFe}_{3} \mathrm{O}_{4} @ I I P-D 1-G 8$} & Des & 99.1 & 99.6 & 99.0 & 98.4 & 98.6 \\
\hline & Ads & 98.3 & 98.8 & 97.9 & 98.8 & 98.5 \\
\hline \multirow[t]{2}{*}{$\mathrm{nFe}_{3} \mathrm{O}_{4} @ I I P-D 2-G 8$} & Des & 99.0 & 98.9 & 98.6 & 98.2 & 98.2 \\
\hline & Ads & 97.5 & 98.3 & 97.9 & 97.4 & 97.9 \\
\hline \multirow[t]{2}{*}{$\mathrm{nFe}_{3} \mathrm{O}_{4} @ N I P-D 0.5-G 8$} & Des & 93.9 & 90.3 & 86.8 & 80.8 & 78.8 \\
\hline & Ads & 72.0 & 69.0 & 58.1 & 48.0 & 43.4 \\
\hline
\end{tabular}

Table 6 Comparison of adsorption properties of different adsorbents $\mathrm{ClO}_{4}{ }^{-}$

\begin{tabular}{|c|c|c|c|c|}
\hline Activated carbon & $\mathrm{NA}^{a}$ & $\mathbf{L}^{b}, \mathrm{~F}^{c}, \mathrm{~T}^{d}$ & $8.04-13.00$ & 36 \\
\hline Cationic surfactant loaded activated carbon & Cationic surfactant & $\mathrm{NA}^{a}$ & $21.14-29.59$ & 8 \\
\hline $\mathrm{nFe}_{3} \mathrm{O}_{4} @ N I P-D 0.5-G 8$ & $-\mathrm{NH}_{2}^{+},-\mathrm{NH}_{3}^{+}$ & $\mathrm{L}^{b}$ & 60.6 & This work \\
\hline $\mathrm{nFe}_{3} \mathrm{O}_{4} @ I I P-D 0-G 8$ & $-\mathrm{NH}_{2}^{+},-\mathrm{NH}_{3}^{+}$ & $\mathrm{L}^{b}$ & 83.3 & This work \\
\hline $\mathrm{nFe}_{3} \mathrm{O}_{4} @ I I P-D 0.5-G 8$ & $-\mathrm{NH}_{2}^{+},-\mathrm{NH}_{3}^{+}$ & $\mathrm{L}^{b}$ & 111.1 & This work \\
\hline
\end{tabular}

$\mathrm{ClO}_{4}{ }^{-}$under similar conditions are summarized in Table 6. The results indicate that the as-prepared $\mathrm{nFe}_{3} \mathrm{O}_{4} @$ IIPs in this work has 3.7-14 times of adsorption capacity as that of other adsorbents reported in the literature, and twice as that of the nonprinted one, i.e., $\mathrm{nFe}_{3} \mathrm{O}_{4} @$ @IP-D0.5-G8. Hence, the newly developed $\mathrm{nFe}_{3} \mathrm{O}_{4} @$ @IIPs has promising potential applications in the removal of $\mathrm{ClO}_{4}{ }^{-}$from environmental water.

\section{Conclusion}

A series of novel protonated amino functionalized core-shell ionic imprinted magnetic polymers $\left(\mathrm{nFe}_{3} \mathrm{O}_{4} @ I I P s\right)$ was controlled prepared by ultrasonic assisted suspension polymerization and surface imprinting technique. The asprepared $\mathrm{nFe}_{3} \mathrm{O}_{4} @$ IIPs exhibited a homogeneous morphology, highly selective recognition, strong affinity ability, and high magnetic responsiveness for the adsorption of $\mathrm{ClO}_{4}{ }^{-}$in aqueous. The adsorption mechanism of the $\mathrm{ClO}_{4}{ }^{-}$ onto the $\mathrm{nFe}_{3} \mathrm{O}_{4} @$ @IIPs is mainly related to ion exchange and electrostatic attraction, in which the protonated amino groups and imprinting cavities play a cooperative role in the adsorption of $\mathrm{ClO}_{4}{ }^{-}$.

\section{Conflicts of interest}

There are no conflicts to declare.

\section{Acknowledgements}

We would like to thank the National Natural Science Foundation of China (51608479), the National Natural Science Foundation of Zhejiang Province (LY14B04003), the National Natural Science Foundation of Ningbo (2014A610092), the National College Students' innovation and entrepreneurship training program (201713022009), the Xinmiao Students' innovation training program of Zhejiang Province (2017R401181) for the financial support.

\section{References}

1 L. Yao, L. X. Yang, J. M. Chen, K. Toda, X. F. Wang, J. M. Zhang, D. Yamasaki, Y. Nakamura, X. Sui, L. F. Zheng, L. Wen, C. H. Xu and W. X. Wang, Levels, indoor-outdoor relationships and exposure risks of airborne particle-associated perchlorate and chlorate in two urban areas in Eastern Asia, Chemosphere, 2015, 135, 31-37.

2 V. I. Furdui, J. C. Zheng and A. Furdui, Anthropogenic Perchlorate Increases since 1980 in the Canadian High Arctic, Environ. Sci. Technol., 2018, 52, 972-981.

3 W. A. Jackson, S. X. Wang, B. Rao, T. Anderson and N. L. Estrada, Heterogeneous Production of Perchlorate and Chlorate by Ozone Oxidation of Chloride: Implications on the Source of (Per)Chlorate in the Solar System, Environ. Sci. Technol., 2018, 2, 87-94. 
4 P. Kumarathilaka, C. Oze, S. P. Indraratne and M. Vithanage, Perchlorate as an emerging contaminant in soil, water and food, Chemosphere, 2016, 150, 667-677.

5 J. A. Carr, S. Murali, F. Hua, W. L. Goleman, D. L. Carr, E. E. Smith and M. Wages, Changes in gastric sodiumiodide symporter (NIS) activity are associated with differences in thyroid gland sensitivity to perchlorate during metamorphosis, Gen. Comp. Endocrinol., 2015, 219, 16-23.

6 R. Epsztein, C. Desitti, M. Beliavski, S. Tarre and M. Green, Co-reduction of nitrate and perchlorate in a pressurized hydrogenotrophic reactor with complete $\mathrm{H}-2$ utilization, Chem. Eng. J., 2017, 328, 133-140.

7 M. C. Gao, S. Wang, Y. Ren, C. J. Jin, Z. L. She, Y. G. Zhao, S. Y. Yang, L. Guo, J. Zhang and Z. W. Li, Simultaneous removal of perchlorate and nitrate in a combined reactor of sulfur autotrophy and electrochemical hydrogen autotrophy, Chem. Eng. J., 2016, 284, 1008-1016.

8 S. Y. Lin, W. F. Chen, M. T. Cheng and Q. Li, Investigation of factors that affect cationic surfactant loading on activated carbon and perchlorate adsorption, Colloids Surf., A, 2013, 434, 236-242.

9 X. M. Wu, Y. L. Wang, L. L. Xu and L. Lv, Removal of perchlorate contaminants by calcined $\mathrm{Zn} / \mathrm{Al}$ layered double hydroxides: equilibrium, kinetics, and column studies, Desalination, 2010, 256, 136-140.

10 Y. H. Xie, S. Y. Li, F. Wang and G. L. Liu, Removal of perchlorate from aqueous solution using protonated crosslinked chitosan, Chem. Eng. J., 2010, 156, 56-63.

11 H. G. Zhang, T. Li, Z. Q. Yang, M. H. Su, L. Hou, D. Y. Chen and D. G. Luo, Highly efficient removal of perchlorate and phosphate by tailored cationic metal-organic frameworks based on sulfonic ligand linking with $\mathrm{Cu}-4,4^{\prime}$-bipyridyl chains, Sep. Purif. Technol., 2017, 188, 293-302.

12 K. D. Hurley and J. R. Shapley, Efficient heterogeneous catalytic reduction of perchlorate in water, Environ. Sci. Technol., 2007, 41, 2044-2049.

13 R. Mahmudovr, Y. Shu, S. Rykov, J. G. Chen and C. P. Huang, The reduction of perchlorate by hydrogenation catalysts, Appl. Catal., B, 2008, 81, 78-87.

14 Z. Xiong, D. Y. Zhao and G. Pan, Rapid and complete destruction of perchlorate in water and ion-exchange brine using stabilized zero-valent iron nanoparticles, Water Res., 2007, 41, 3497-3505.

15 D. L. Wu, P. He, X. H. Xu, M. Zhou, Z. Zhang and Z. Houda, The effect of various reaction parameters on bioremediation of perchlorate-contaminated water, J. Hazard. Mater., 2008, 150, 419-423.

16 J. Q. Fu, L. X. Chen, J. H. Li and Z. Zhang, Current status and challenges of ion imprinting, J. Mater. Chem. A, 2015, 3, 13598-13627.

17 R. Gil, C. G. Amorim, L. Crombie, P. K. T. Lin, A. Araffljo and M. C. Montenegro, Study of a Novel Bisnaphthalimidopropyl Polyamine as Electroactive Material for Perchlorate-selective Potentiometric Sensors, Electroanalysis, 2015, 27, 2809-2819.

18 X. Zuo, D. Mosha, S. J. Archibald, A. K. McCasland, A. M. Hassan, R. S. Givens and D. H. Busch, Toward the soil poultice and a new separations methodology: Rebinding of macrocyclic metal complexes to molecularly imprinted polymers specifically templated via noncovalent interactions, J. Coord. Chem., 2005, 58, 21-39.

19 T. S. Anirudhan and J. C. Binusreejayan, pH and magnetic field sensitive folic acid conjugated protein-polyelectrolyte complex for the controlled and targeted delivery of 5fluorouracil, J. Ind. Eng. Chem., 2018, 57, 199-207.

20 M. E. Mahmoud, A. A. Yakout, K. H. Hamza and M. M. Osman, Novel nano- $\mathrm{Fe}_{3} \mathrm{O}_{4}$-encapsulateddioctylphthalate and linked-triethylenetetramine sorbents for magnetic solid phase removal of heavy metals, J. Ind. Eng. Chem., 2015, 25, 207-215.

21 A. Magdy, Y. O. Fouad, M. H. Abdel-Aziz and A. H. Konsowa, Synthesis and characterization of $\mathrm{Fe}_{3} \mathrm{O}_{4} /$ kaolin magnetic nanocomposite and its application in wastewater treatment, J. Ind. Eng. Chem., 2017, 56, 299-311.

22 S. D. Pan, H. Y. Shen, Q. H. Xu, J. Luo and M. Q. Hu, Surface mercapto engineered magnetic $\mathrm{Fe}_{3} \mathrm{O}_{4}$ nanoadsorbent for the removal of mercury from aqueous solutions, $J$. Colloid Interface Sci., 2012, 365, 204-212.

23 H. Y. Shen, Z. X. Chen, Z. H. Li, M. Q. Hu, X. Y. Dong and Q. H. Xia, Controlled synthesis of 2,4,6-trichlorophenolimprinted amino-functionalized nano- $\mathrm{Fe}_{3} \mathrm{O}_{4}$-polymer magnetic composite for highly selective adsorption, Colloids Surf., A, 2015, 481, 439-450.

24 Y. Wang, S. Ye, S. S. Lv, J. L. Zhang and X. S. Ye, Preparation of ion imprinted $\mathrm{Fe}_{3} \mathrm{O}_{4} @$ IIP(MMA-HPMA-DVB) magnetic composite and its selective adsorption to Ni(II), Acta Mater. Compositae Sin., 2017, 34, 2846-2855.

25 X. Q. Li, L. Fang, M. N. Zhang and Y. D. Liu, Measurement of Perchlorate Concentration in Groundwater Using Methylene Blue Complexation- Spectrophotometry, Environ. Sci. Technol., 2014, 37, 96-99.

26 H. Y. Shen, S. D. Pan, Y. Zhang, X. L. Huang and H. X. Gong, A New Insight on the Adsorption Mechanism of Aminofunctionalized Nano- $\mathrm{Fe}_{3} \mathrm{O}_{4}$ Magnetic Polymers in $\mathrm{Cu}(\mathrm{II})$, Cr(VI) Co-existing Water System, Chem. Eng. J., 2012, 183, 180-191.

27 J. Febrianto, A. N. Kosasih, J. Sunarso, Y. H. Ju, N. Indraswati and S. Ismadji, Equilibrium and kinetic studies in adsorption of heavy metals using biosorbent: A summary of recent studies, J. Hazard. Mater., 2009, 162, 616-645.

28 Y. S. Ho, Review of second-order models for adsorption systems, J. Hazard. Mater., 2006, 136, 681-689.

29 S. H. Huang and D. H. Chen, Rapid removal of heavy metal cations and anions from aqueous solutions by an aminofunctionalized magnetic nano-adsorbent, J. Hazard. Mater., 2009, 163, 174-179.

30 W. Zhang, L. Qin, X. W. He, W. Y. Li and Y. K. Zhang, Novel surface modified molecularly imprinted polymer using acryloyl- $\beta$-cyclodextrin and acrylamide as monomers for selective recognition of lysozyme in aqueous solution, $J$. Chromatogr. A, 2009, 1216, 4560-4567.

31 Y. G. Zhao, H. Y. Shen, S. D. Pan, M. Q. Hu and Q. H. Xia, Preparation and characterization of amino-functionalized 
nano- $\mathrm{Fe}_{3} \mathrm{O}_{4}$ magnetic polymer adsorbents for removal of chromium(VI) ions, J. Mater. Sci., 2010, 49, 5291-5301.

32 C. Liu and X. W. Lv, Identification of explosives by infrared spectroscopy, Chem. Propellants Polym. Mater., 2017, 15, 82-84.

33 K. Y. Foo and B. H. Hameed, Review: insights into the modeling of adsorption isotherm systems, Chem. Eng. J., 2010, 156, 2-10.

34 M. Q. Hu, H. Y. Shen, Z. H. Jiang, Y. F. Wang, L. Y. Wang and Q. Jiang, One-pot solvothermal preparation of ethylenediamine-functionalized nanochain and its adsorption-in situ degradation of 2,4,6-trichlorophenol, Desalin. Water Treat., 2018, 102, 253-263.
35 M. C. Simoes, K. J. Hughes, D. B. Ingham, L. Ma and M. Pourkashanian, Estimation of the Thermochemical Radii and ionic volumes of Complex Ions, Inorg. Chem., 2017, 56, 7566-7573.

36 N. Lu, N. Y. Gao and X. Huang, Adsorption of Perchlorate in Water by Granular Activated Carbon and Impact Factors Analysis, Environ. Sci., 2008, 29, 1572-1577.

37 Y. X. Wu, Y. W. Cheng, C. G. Hubbard, S. Hubbarda and J. B. Ajo-Frankli, Biogenic sulfide control by nitrate and (per)chlorate - A monitoring and modeling investigation, Chem. Geol., 2018, 476, 180-190. 